\title{
Narrative review of penile prosthetic implant technology and surgical results, including transgender patients
}

\author{
Michael Polchert, Brian Dick, Omer Raheem \\ Department of Urology, Tulane University School of Medicine, New Orleans, LA, USA \\ Contributions: (I) Conception and design: O Raheem; (II) Administrative support: O Raheem; (III) Provision of study materials or patients: None; (IV) \\ Collection and assembly of data: M Polchert, B Dick; (V) Data analysis and interpretation: M Polchert, B Dick; (VI) Manuscript writing: All authors; \\ (VII) Final approval of manuscript: All authors. \\ Correspondence to: Dr. Omer Raheem, MD, MSc, MCh Urol, MRCSI. Director of Mens Health, Assistant Professor of Urology, Department of \\ Urology, Tulane University School of Medicine, 1430 Tulane Ave. 8642 Room 3514, New Orleans, LA 70112, USA. Email: oraheem@tulane.edu.
}

\begin{abstract}
Over the past 40 years, the technological and surgical advancements in penile prostheses have led to increased patient satisfaction rates and decreased complication and infection rates. In cis males with erectile dysfunction (ED), these technological improvements tremendously improve quality of life. In female to male transgender patients, prostheses provide the ability to engage in penetrative intercourse and to urinate standing. This review evaluates technological and surgical advancements in penile prosthetics in the context of documented patient satisfaction and complication rates from prosthesis surgeries. Retrospective studies of penile implant usage in female to male gender-affirming surgeries report that infection and complication rates are higher than those seen in cis males. There are newer prostheses developed specifically for female to male reassignment surgeries, but outcome data is limited. Continued research and development are needed to develop more efficacious penile implantation options for gender affirmation surgery.
\end{abstract}

Keywords: Penile prosthesis surgery; penile implants; transgender

Submitted Sep 18, 2020. Accepted for publication Nov 20, 2020.

doi: $10.21037 /$ tau-20-1279

View this article at: http://dx.doi.org/10.21037/tau-20-1279

\section{Introduction}

Prior reviews of penile prosthesis surgery results that are available in the literature often stratify findings only according to prosthesis type (e.g., two-piece and three-piece prostheses) and do not delineate results by model type (e.g., Coloplast Titan). Furthermore, the urological literature has historically published separate reviews of prosthesis implantation results for either cis or transgender males. This narrative review examines technological and surgical developments in penile prosthesis implants-with a focus on retrospective results of penile prosthesis surgeries by implant type and model in both cis and transgender males.

The first autologous penile implant was designed by the Russian surgeon Nikolaj A. Bogaraz using a patient's own rib cartilage in 1936. Nearly 40 years later, in 1973, the Small-Carrion malleable prosthesis and first inflatable penile prosthesis (IPP) were introduced. Today, penile implants have become the gold standard for several morbidities in men, including medically refractory erectile dysfunction (ED) and penile trauma. There are three main types of penile devices available for prosthesis implantation: the semi-rigid or malleable, the two-piece inflatable, and the three-piece inflatable. Each prosthesis involves a unique surgical approach and technique for implantation. The three-piece prosthesis is considered by many urologists to be superior to the two-piece prosthesis and is reportedly used in over $80 \%$ of penile implant surgeries (1). Additionally, three-piece IPPs are also the most common implanted prosthetic penile devices in transgender males (2). To date, penile prosthesis technology has culminated in the three-piece prosthesis-yet the best implant for transgender men undergoing phalloplasty is still being studied. The progression of penile prosthesis technology presented 
Table 1 Modern penile implants

\begin{tabular}{|c|c|c|c|c|c|c|}
\hline Implant type & Manufacturer & Model & Antibacterial Design & $\begin{array}{l}\text { Cylinder lengths } \\
\text { (cm) }\end{array}$ & $\begin{array}{l}\text { Cylinder } \\
\text { diameters (mm) }\end{array}$ & Year released \\
\hline \multirow[t]{5}{*}{ Semi-rigid } & Mentor (Coloplast) & Small Carrion Prosthesis & - & \multicolumn{2}{|l|}{ Discontinued model } & 1975 \\
\hline & Dacomed & Omniphase/Duraphase & - & \multicolumn{2}{|l|}{ Discontinued model } & 1986 \\
\hline & Mentor (Coloplast) & $\begin{array}{l}\text { Acu-Form (predecessor } \\
\text { to Genesis) }\end{array}$ & - & \multicolumn{2}{|l|}{ Discontinued model } & 1998 \\
\hline & AMS-BSCI & Spectra $^{\mathrm{TM}}$ (2009) & None & $12,16,20$ & $9.5,12,14$ & 2009 \\
\hline & $\mathrm{BSCl}$ & Tactra & - & $\begin{array}{l}\text { Cut to length } \\
\text { sizing }\end{array}$ & - & 2019 \\
\hline $\begin{array}{l}\text { Two-piece } \\
\text { inflatable }\end{array}$ & AMS-BSCI & Ambicor $^{\mathrm{TM}}$ & None & $14,16,18,20,22$ & $12.5,14,15.5$ & 1994 \\
\hline \multirow[t]{5}{*}{$\begin{array}{l}\text { Three-piece } \\
\text { inflatable }\end{array}$} & Coloplast & Titan & $\begin{array}{l}\text { Hydrophilic } \\
\text { polyvinylpyrrolidone }\end{array}$ & $\begin{array}{l}\text { 11, 14-28 (even } \\
\text { sizes) }\end{array}$ & $13,14,15,16$ & \multirow{4}{*}{$\begin{array}{l}1983 \text { first } \\
\text { version of } \\
\text { 3-piece release }\end{array}$} \\
\hline & & Titan NB & coating & 11,14 & 11,12 & \\
\hline & & Titan OTR & & $\begin{array}{l}\text { 11, 14-28 (even } \\
\text { sizes) }\end{array}$ & $13-16$ & \\
\hline & & Titan OTR NB & & 11,14 & 11,12 & \\
\hline & AMS-BSCl & AMS $700^{\mathrm{TM}} \mathrm{CX}$ & Inhibizone ${ }^{\mathrm{TM}}$ - & $12,15,18,21$ & $12-18$ & $\begin{array}{l}1983 \text { first } \\
\text { version of } \\
\text { 3-piece released }\end{array}$ \\
\hline
\end{tabular}

in this review will help better evaluate implant efficacy metrics (e.g., infection rates and patient satisfaction) in cis male and transgender recipients. Table 1 identifies the most common penile prosthesis models implanted by surgeons. Figure 1 highlights historical milestones in the surgical and technological advancement of penile prostheses. We present the following article in accordance with the Narrative Review Reporting Checklist (Available at: http://dx.doi. org/10.21037/tau-20-1279).

\section{Methods}

A scientific literature search utilizing Medline was performed to comprehensively determine technological advancements and surgical results for penile implants from 1973 - the advent of modern malleable and inflatable penile prostheses-to the present time. Keywords including "penile prosthesis surgery", "malleable penile prosthesis", "inflatable penile prosthesis", "transgender penile prosthesis", "twopiece IPP", and "three-piece IPP" were used to identify appropriate articles to include in this narrative review. Only peer reviewed articles published in English were included. Seventy six publications were included. Studies which presented results from retrospective penile prosthesis placements were prioritized for their value in evaluating comparative metrics (e.g., infection and complication rates) across penile prosthesis types and models.

\section{Malleable prostheses}

\section{Historical perspective}

Malleable penile implants were the first mainstream penile implants of the modern era. The advent of new polymers 


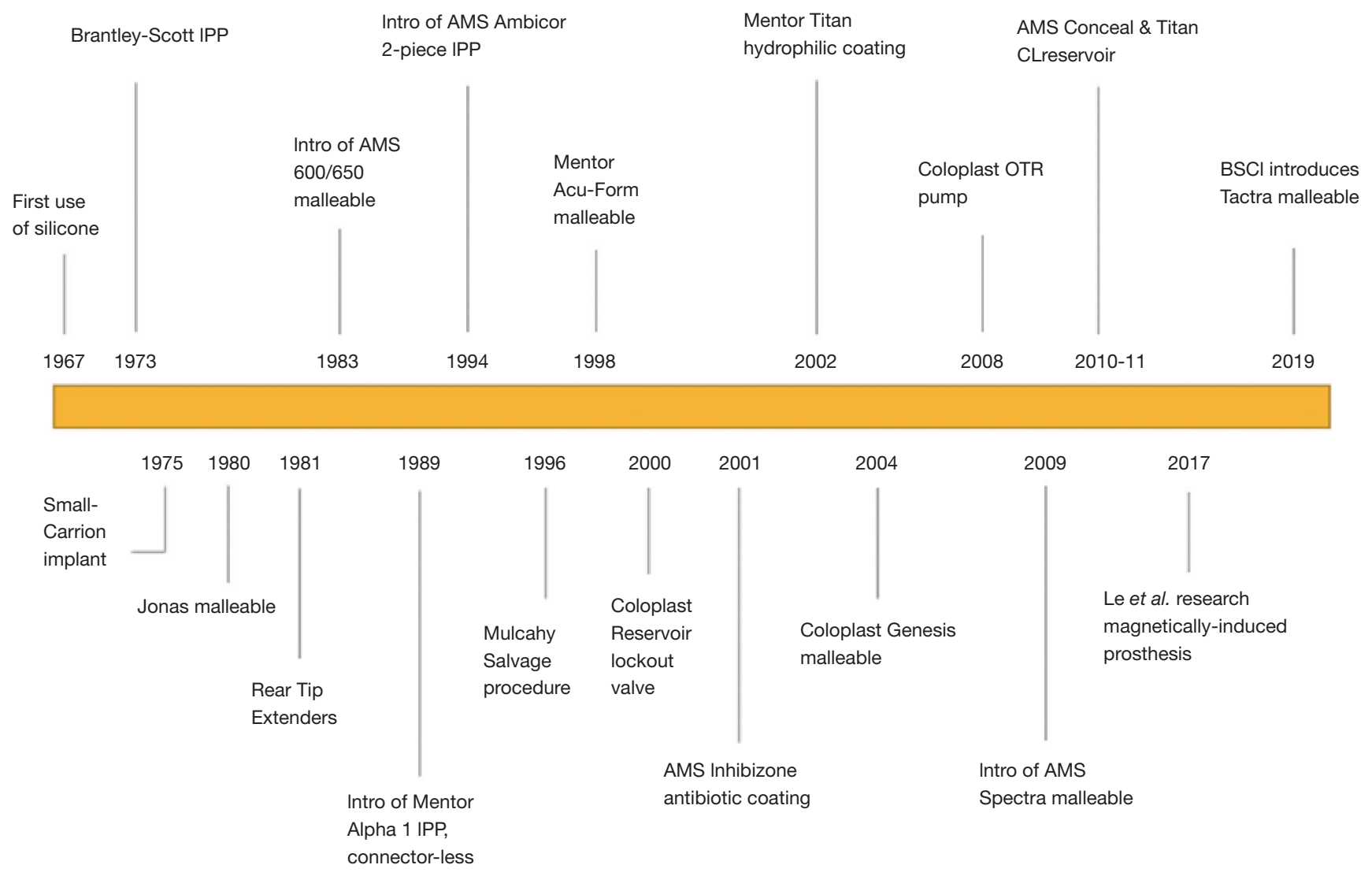

Figure 1 Developmental milestones of modern penile prostheses.

in the late 1960s allowed for the creation of a silicone prosthesis that was implanted through a dorsal penile incision. In 1973, Drs. Hernan Carrion and Michael Small were some of the first researchers to publish on successful malleable penile prosthetic implantation in patients (3). The Small-Carrion prosthesis was made of a silicone-sponge interior encased in a medical-grade silicone shell, available in four lengths ranging from $12-15.8 \mathrm{~cm}$ and two diameters, 0.9 and $1.1 \mathrm{~cm}$. Drs. Carrion and Small used a perineal approach for implantation, to avoid previously documented complications with the dorsal approach and to eliminate penile scarring. For malleable prosthesis recipients, the penis remains in a semi-rigid state permanently, and the patient can bend the prosthesis upwards in order to engage in sex.

\section{Technological development of malleable prostheses}

The Jonas malleable penile prosthesis, considered to be the first true marketable malleable implant, was introduced in
1980 (4). This implant included a malleable silver core, to allow for the phallus to hang in a more dependent fashion when not needed for intercourse, while still having the capability to project at a right angle prior to sex. Results from the Jonas penile prosthesis implantation using a penoscrotal approach were reported from 69 patients between 1980-1982, with only two reported cases of post-operative infection (5). In 1983, the AMS (now owned by Boston Scientific) malleable 600 model series malleable penile prosthesis was introduced. The AMS device contained a stainless steel wire core with a silicone rubber exterior; it included a cone-shaped proximal cylinder design and distal tapered end to conform to a patient's crus and glans, respectively (6).

Early evaluations of patient satisfaction with Jonas and AMS prostheses implants indicated high overall satisfaction rates $(\sim 90 \%)$, but lesser satisfaction with respect to concealment and fit of clothing with the implant in place ( 65\%) (6). In 1992, the Duraphase II penile prosthesis was invented, which consisted of a polyethylene disc exterior 


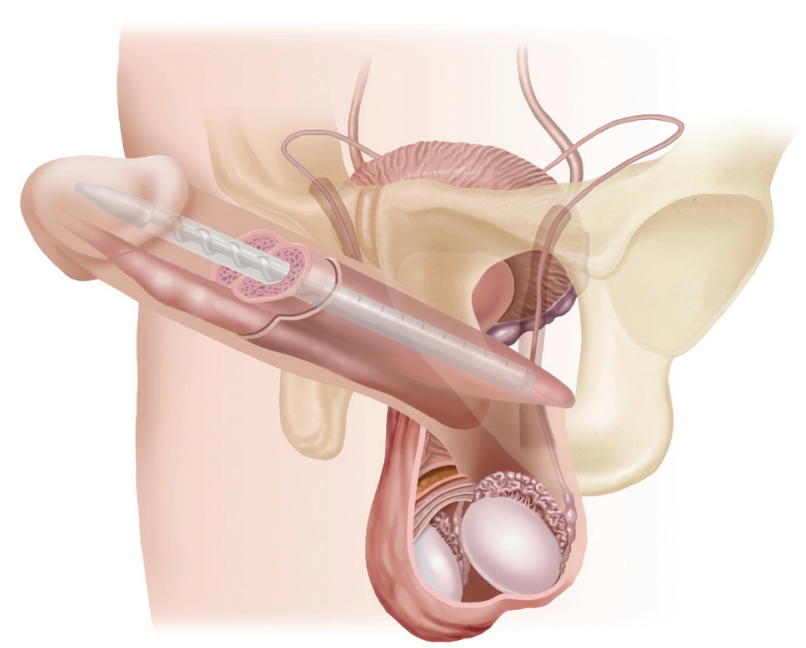

Figure 2 Genesis malleable penile implant. Source: Coloplast.

surrounding a metal cable core; this model was designed to improve upon the mechanical strength, concealment, and positional memory of earlier implant models. Along with the American Medical Systems 600M and 650 devices, the Duraphase-II remained a popular penile implant option throughout the 1990s.

In 2004 and 2009, respectively, the Coloplast Genesis (Figure 2) and AMS Spectra malleable implants were introduced. These continue to be the most commonly used malleable prostheses in the United States (7). Malleable prostheses are most commonly implanted in patients who have difficulty with the hand dexterity involved in pumping a two- or three-piece prosthesis and in spinal cord injury patients (8). The prostheses are also used in the malleable implant salvage technique (MIST) described by Mulcahy.

\section{New Tactra and touchless memory shape prostheses}

In April 2019, the U.S. Food and Drug Administration approved Boston Scientific's new Tactra malleable penile prosthesis. The device has a nickel-titanium alloy core encased by a proprietary dual-layer silicone exterior. The implant has trimmable exterior etchings for corporal size optimization during the operation as well as insertionfit rear tip extenders (RTEs) for secure crural placement. The Tactra prosthesis is indicated to have an enhanced ease of implantation, a high level of rigidity for coitus, as well as dependable concealment for periods outside of sexual function. The Tactra prosthesis is currently being investigated in a post-market clinical trial study of approximately 140 patients.
In an effort to simplify current IPP technology, Le et al. are investigating a novel "touchless" memory shape IPP with a nickel-titanium alloy (Nitinol) exoskeleton (9). Through an external magnetic inducer wand, the nitinol core within the implant expands and hardens, allowing the patient to achieve an erection. This process is known as magnetic induction, whereby a magnetic field excites metal molecules to produce an electric current and heat. The increase in heat causes the Nitinol to expand into an "erect" state. Initial proof of concept experiments compared the device to existing inflatable and malleable penile prostheses and found a similar resistance to buckling [2.62 kilogram-force (kgf.)] as the conventional inflatable (1.42 kgf) prosthesis (10). Subsequent experiments by the Le et al. research team focused on efficacy of device activation. Most recently investigators found that the magnetic field penetrated tissue and activated the IPP in under 45 seconds (9). Experts have noted skepticism of this new device due to potential damage to tissue as a result of internal temperature increases and complications associated with device activation (11). Research into this radically novel type of prosthesis is in very early stages. Though apparent pros include fewer moving parts, less invasive activation, and potentially reduced mechanical failure, it remains to be seen how big of a role this new technology will play.

\section{Surgical considerations and post-operative results for malleable implants}

The Coloplast Genesis has design specifications including a hydrophilic coating which allows surgeons to customize antibiotic preparation. It remains the only malleable implant with an antibiotic/hydrophilic coating. In research comparing the Genesis and AMS Spectra models, no statistically significant differences were identified regarding the 11 criteria enumerated in the Erectile Dysfunction Inventory of Treatment Satisfaction (EDITS) questionnaire.

Semi-rigid/malleable prostheses are implanted through a distal sub-coronal penile approach. To prevent excessive bending of the device during implantation, it is necessary to use slightly larger corporal incisions than those used for inflatable cylinders (12).

Malleable prostheses play a vital role in the Mulcahy salvage protocol (13). In this procedure, a malleable device is implanted in the same surgery as IPP removal in attempt to decrease fibrosis and preserve penile length $(14,15)$. This procedure requires less time than re-implantation of a two- 
or three-piece IPP, as well as the theoretical advantage of less components at risk for reinfection (4).

There are multiple studies on post-operative results and patient satisfaction with malleable prostheses. Documented infection rates range from $1.4 \%$ to $8.3 \%$. Published values of erosion (1.4-5.1\%) and mechanical dysfunction $(0.5 \%$ and $12 \%)$ are also documented. General patient satisfaction rates in retrospective surveys range from $69-86.6 \%$ depending on malleable model. Table 2 presents post-operative results from malleable penile prosthesis implantation surgeries (16-20).

\section{Inflatable prostheses}

\section{Two-piece IPP}

\section{Historical perspective}

The development of IPPs began with the release of the Hydroflex inflatable one-piece penile prosthesis in 1985 (21). The AMS Dynaflex was released five years later in 1990. High rates of mechanical failure requiring device explantation were reported for the one-piece IPP and survival for multicomponent IPPs was found to be greater $(22,23)$.

The Mentor GFS (Girth, Flacidity, and Simplicity) two-piece IPP was first introduced in 1988. This IPP featured a combined fluid reservoir and pump implanted in the scrotum. From limited published studies, patients implanted with the device had a satisfaction rate of $86 \%$; mechanical malfunctions were reported by $14-32 \%$ of implanted patients $(24,25)$. The Mark II was the subsequent iteration of the device which eliminated the use of tubing connectors (26).

\section{Technological development of two-piece prostheses}

The Ambicor prosthesis (Boston Scientific), introduced in 1994, upgraded the pumping system of the Dynaflex one-piece prosthesis to obviate the need of including the reservoir within the penile anatomy. Instead, a separate scrotal pump inflated the cylinders to achieve an erect state. Subsequent improvements to the prosthesis came in 1998 and included reshaping of the RTE for more secure crural positioning as well as addition of extra protection to tubing exiting the pump. These improvements were investigated in a study of 146 men with a mean postoperative followup of 38 months. The subjects reported overall satisfaction of $88 \%$ in a modified EDITS survey, with $86 \%$ of patients indicating they would recommend the prosthesis to a friend or undergo the surgery again if necessary (27).

Today, the Ambicor two-piece inflatable prosthesis, consisting of parylene-coated cylinders implanted in the corpora and a pump installed in a scrotal Dartos pouch, is the most popular two-piece IPP available in the US. The device is available in diameters ranging from $12.5-15.5 \mathrm{~mm}$, lengths ranging from 14-22 cm, and RTEs ranging from $0.5-3 \mathrm{~cm}$ which can be added to adjust proximal corporal and crural placement. The cylinder is inflated by squeezing the pump and is deflated with activation of a time-pressure valve, manually engaged by bending the penis either upward or downward for approximately 10s. In a recent literature review on two-piece IPPs published in 2018, overall complication rates were reported between $2.1-11.2 \%$; mechanical failure rates from $0.7-6.1 \%$, and infection rates from $0.7-4.8 \%$ (26). A 2018 literature review for Ambicor prosthesis implants placed in the past ten years identified patient satisfaction rates ranging from 75-96.4\% (28).

\section{Surgical considerations and post-operative results for two-piece implants}

Despite the increased demand for 3-piece IPPs and expanded literature on their development and outcomes, two-piece IPPs are an important option for several ED patient populations. Compared to the three-piece IPP which requires approximately 10-14 squeezes to harden, the two-piece Ambicor IPP only requires 3-6 pumps-making it ideal for those who have manual dexterity difficulties and hand strength impairment, such as the elderly (7). Additionally, a two-piece IPP should be considered in patients who have undergone surgeries that can cause retropubic scarring, such as pelvic organ transplants, as this makes intra-abdominal reservoir placement more difficult $(7,29)$.

In spinal cord injury patients, two-piece prostheses provide a convenient solution for urinary management and sexual satisfaction (8). Two-piece IPPs are contraindicated in patients with pre-existing Peyronie's disease as the cylinders may not provide optimum rigidity against heavy plaque deposits and may be difficult to position in the less elastic tunica albuginea (28). Two-piece prostheses have been used to complete neophallus construction surgeries in female to male transgender patients and may have an important role is this population, as will be discussed later in this article.

Studies on post-operative and patient satisfaction results for two-piece IPP implantations were reviewed and are presented in Table 3 (27,29-31). Published infection rates 


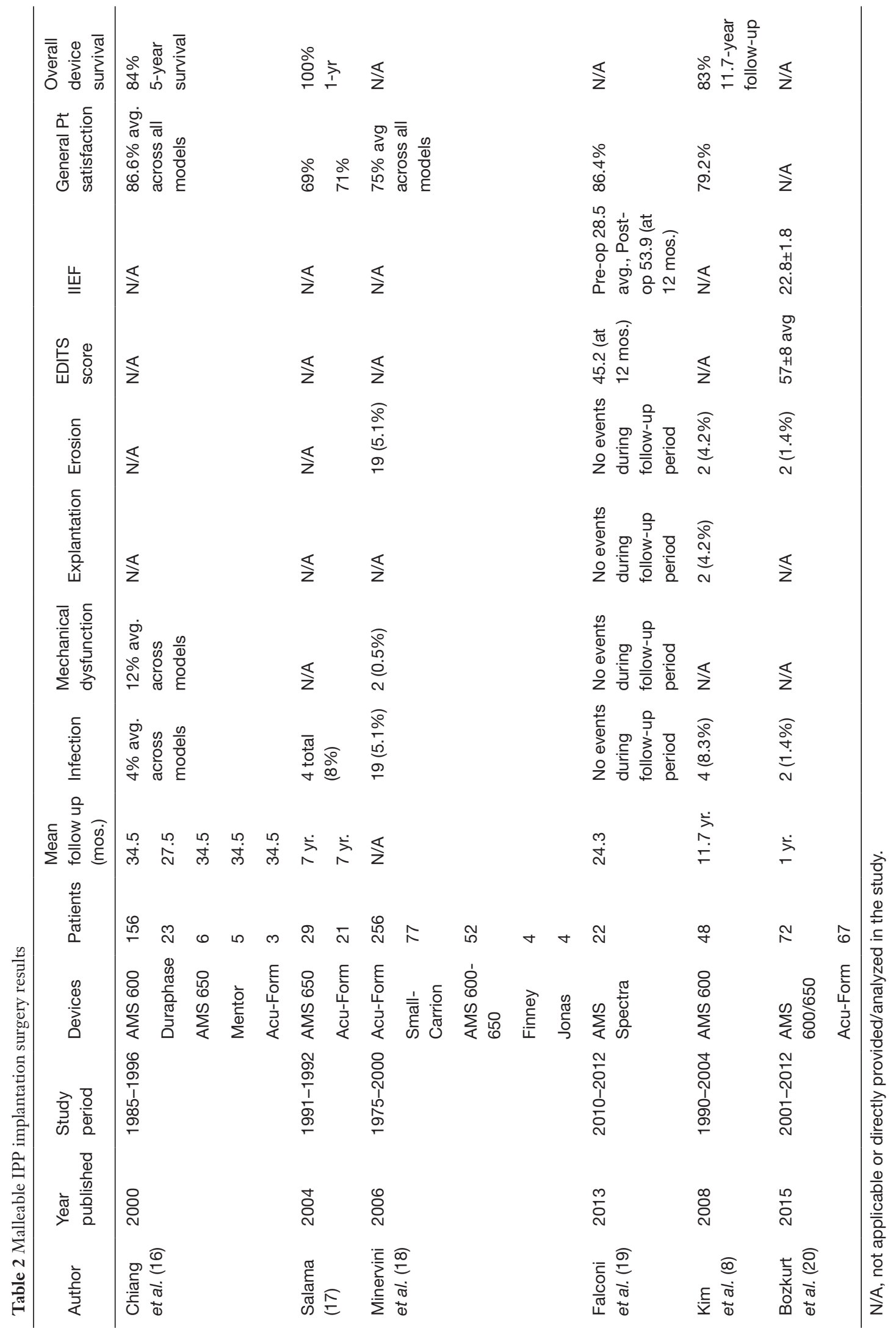




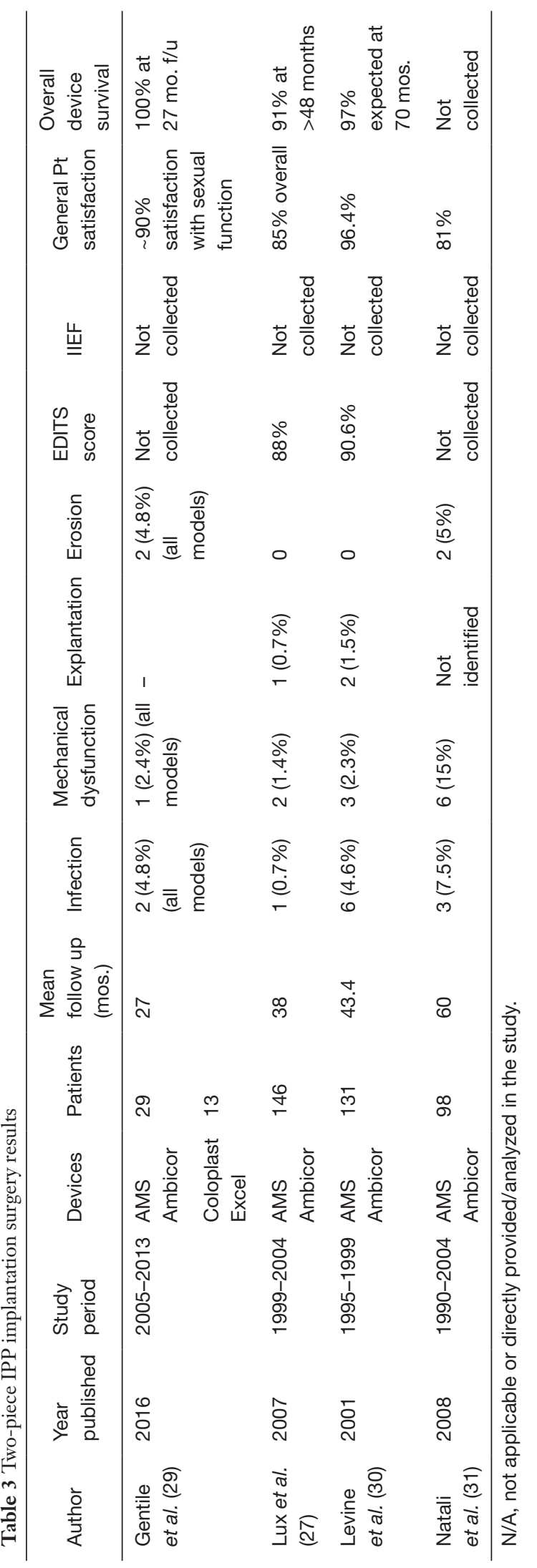

range from $0.7 \%$ to $7.5 \%$. Four cases of erosion and 12 cases of mechanical dysfunction were identified across all combined reviewed studies, which primarily focused on the AMS Ambicor model. General patient satisfaction rates varied from $80-96.4 \%$ across the studies.

\section{Three-piece inflatable prostheses}

\section{Historical perspective}

Three-piece penile prostheses are estimated to account for over $80 \%$ of the market share of penile implants in the US (1). As such, considerable attention will be given to the 3-piece IPP technology and surgical development in this section. Prototypes of three-piece IPP devices were first released in the early 1980's. These devices consisted of the same components which make up the modern 3-piece IPP: dual intra-corporal inflatable cylinders, a scrotal pump, and a fluid reservoir implanted in the abdomen. Threepiece IPPs underwent rapid technological progress through the $80 \mathrm{~s}$ and $90 \mathrm{~s}$, and complication rates dropped from over $50 \%$ at their introduction to only $13 \%$ at a four-year follow-up (32). Three-piece penile prostheses are implanted through either infra-pubic or trans-scrotal approaches. A peno-scrotal approach has advantages including lowered risk of dorsal nerve injury, increased corporal visualization, and better facilitation of scrotal pump placement. Infrapubic approaches have been cited to have decreased device placement time and more direct visualization of reservoir insertion (4).

\section{Technological development of three-piece prostheses Cylinder development}

The first three-piece IPPs were made of silicone or other flexible polymer materials. Poltetrafluoroethylene (PTFE) sleeve coverings, to reduce wear between silicone parts, were introduced in 1983 in the AMS 700 model (33). Recent cylinder improvements include increased prosthesis girth, controlled length expansion potential, and increasingly stable RTEs which snap or screw in place, alleviating the issue of cylinder disconnection from the proximal corpora (34).

In 1987, AMS released its AMS 700 CX model which consisted of a sturdier, 3-ply material design involving an inner bulk silicone base covered by a unidirectional Dacron-Lycra weaved layering (33). This cylinder design resulted in less pressure on the patient's corpora during IPP inflation (35). The dacron-lycra layer in the AMS 700 and similar polyurethane layer of the Titan Coloplast implant 


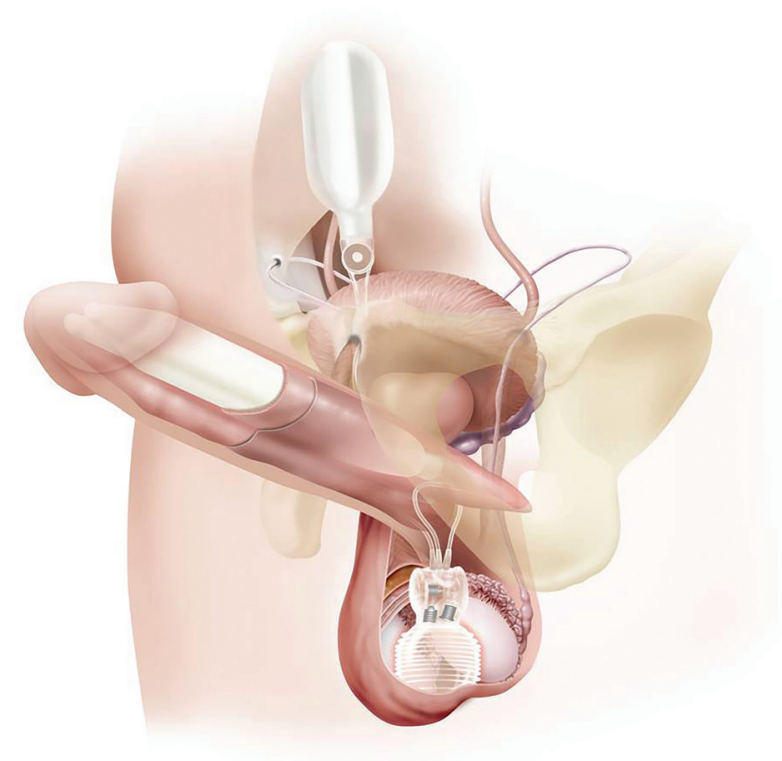

Figure 3 Titan touch three-piece IPP. Source: Coloplast.

are also recommended for patients with tunica albuginea defects to limit aneurysm formation (36). In 2001, AMS included a Parylene microcoating to improve their cylinder performance via increased durability and decreased friction between cylinders. Researchers found that the Parylene coating improved 3-year revision free survival from $78.6 \%$ to $87.4 \%$, when compared with non-coated AMS 700 implants (12).

In 1981, RTEs were added to IPP technology (37). These silicone tips are added to the proximal end of corporal cylinders to allow for more secure placement and decrease cylinder wear. The use of RTEs is called for only in smaller to medium size penises (less than $18 \mathrm{~cm}$ ). In 2006, new RTE design allowed for more secure cylinder placement. Snap fit RTEs by AMS are available in sizes from $0.5-6 \mathrm{~cm}$. Titan cylinders have screw-on RTEs available in sizes from $1-3 \mathrm{~cm}$. The use of RTEs in prosthesis surgery has reportedly increased from $6-8 \%$ in 2000 to $93 \%$ in 2015 (38).

In 1990, AMS introduced the Ultrex cylinders, which allowed for increased cylinder girth expansion from a bidirectional fabric layer (34). The middle fabric layer of the Ultrex IPP was replaced with a stronger material three years later in 1993 (modified Ultrex). These improvements led to increased device reliability and patient satisfaction. A 2002 study compared the modified Ultrex and older
Ultrex model-the modified Ultrex exhibited higher 5 -year estimates of overall $(64.7 \%$ vs. $77.7 \%, \mathrm{P}=0.23)$, mechanical $(70.7 \%$ vs. $93.7 \%, \mathrm{P}=0.017)$, and cylinder survival $(77.7 \%$ vs. $96.2 \%, \mathrm{P}=0.008)$ when compared to the original Ultrex model (39). AMS subsequently changed the name of the Ultrex to the Length Girth Expansion (LGX). The diameter of the proximal ends of the cylinders were narrowed in the LGX model, with allowance for extension with snap on RTEs. In addition to increased girth, the LGX model is also implicated to increase mean penile length postoperatively (40). Narrow cylinders from AMS and Coloplast are also available for patients with smaller penises and/or fibrotic corpora (34). AMS first introduced narrower cylinder models, the 700 CXM and CXR models, in 1990. The Coloplast Titan (Figure 3) also offers a narrow base model. Both the AMS and Coloplast reduced girth models are suggested for multi-component prosthesis implantation in patients with significant corporal scarring and Peyronie's Disease (41).

\section{Antibacterial coatings}

As with any surgically implanted device, infection is a concern in IPP placement. To help prevent infection, manufacturers began making IPP implants with hydrophilic material that can be soaked in antibiotic solutions. IPP antibacterial coatings elute from the device throughout approximately two weeks after device implantation. Antibacterial delivery through IPPs is an important aspect of implant design, said to have reduced rates of infection from $3-5 \%$ to $1-2 \%$ (42).

AMS first introduced the Inhibizone ${ }^{\mathrm{TM}}$ coating to its implants in 2001. This coating is a combination of Minocycline Hydrochloride and Rifampin, and has been shown to be particularly effective against Staphylococcus, the most common source of device infection (34). Reported infection rates for primary implants range from $1 \%$ to $1.61 \%(43,44)$.

Shortly thereafter Coloplast introduced its hydrophilic coating, polyvinylpyrrolidone, to all its Titan implants in 2002. This coating reduces bacterial adherence and absorbs any water-based antibiotic chosen by the surgeon before implantation (45). Comparison of Titan coated implants vs. non-coated implants revealed a lower infection rate $(\mathrm{P}=0.033)$ in the Titan coated $(1.06 \%$ of 2,357 patients) compared with non-coated implants $(2.07 \%$ of 482 patients) (45). Several studies performed on the Coloplast Titan implant compare the efficacy of different adsorbed antibacterial cocktails to prevent infection when 
compared with the AMS Inhibizone implant $(46,47)$. Experts recommend that the Coloplast Titan is coated with a rifampin/gentamicin mixture prior to implantation $(47,48)$.

\section{Pump development}

In 2004, the Tactile pump was introduced to three-piece IPPs. This innovation allowed for increased volumetric fluid per squeeze, enhanced scrotal pump manipulation by implant patients, and easier device deflation (34). A blinded study of the older 700 Series pump and the Tactile pump reported that patients had an easier time locating the pump $(100 \%, \mathrm{P}<0.001)$ and deflating the pump $(96.7 \%$, $\mathrm{P}<0.001)$ (49). AMS introduced the Momentary Squeeze pump in 2006, which facilitated quicker and easier pump deflation. The Momentary Squeeze mechanism allowed for full deflation in $2-4$ seconds and only required a single press of the depressurization button, improving on the older model which required continuous pump deflation as well as simultaneous squeezing of cylinders, to fully deactivate the IPP. This new design also included a smaller pump body and lockout valve. A study of the 10-year survival rate of the AMS 700CX IPPs with the touch pump and the momentary squeeze pumps identified respective device survival rates of $77.6 \%$ and $82.5 \%$. Nearly $91 \%$ of patients continued to use the device and were engaging in sexual intercourse (35).

Coloplast received approval for its One Touch Release (OTR) pump system in 2008. This improvement included deflation "Touch Pads" on either side of the pump, providing palpable features to deflate the pump with one hand. The OTR pump was smaller size than prior models and made from a stronger silicone material, to improve device toughness.

\section{Reservoir development}

Auto-inflation of reservoirs is an IPP complication thought to be caused by the formation of a tissue capsule around the reservoir (50). In 2000, Coloplast introduced a textured reservoir to limit encapsulation by increasing surface area (34). The same year, Coloplast further upgraded the reservoir design to include a Lock-out Valve ${ }^{\mathrm{TM}}$, also meant to prevent auto inflation (33). This was shown to successfully reduce auto inflation from $11 \%$ in the older technology to $1.3 \%$ in the newer technology (22). While auto-inflation can be considered a benign complication of IPP placement, more serious cases may require a capsulotomy to free up and reposition the reservoir (24).

Reservoir palpability is another major concern of IPP recipients. For this reason, the reservoir is traditionally placed in the Space of Retzius where it is imperceptible to the patient. However, placement into this space is performed blindly and places the patient at risk of bowel, bladder, or vascular injury. To avoid injury, implanters may choose to place the reservoir in an alternate, ectopic location (51). Companies designed new reservoirs that would remain flat when filled (Conceal reservoir, AMS and Cloverleaf reservoir, Coloplast) to minimize reservoir palpability in ectopic locations. In 2015, Coloplast's Cloverleaf reservoir became the first to receive FDA approval for labeling instructions to include "ectopic" placements.

\section{Latest three-piece IPP developments}

Boston Scientific Corporation has submitted several new patents to improve upon aspects of the three-piece IPP design. Patent \#10285815, \#9522065, and \#9889010 describe a dual poppet valve assembly to ensure better filling of the pump bulb and general fluid flow throughout the hydraulic system. Patent \#9808343 describes a piezoelectric pump powered by an external magnetic field. This would assist patients with easier IPP inflation, and potentially eliminate any residual complaints associated with locating the pump manually and soreness during inflation. New developments with this patent remain to be seen.

The Zephyr Surgical Implant (ZSI) 475 is a newer threepiece IPP introduced to the international market, which has not yet been approved by the FDA. The implant offers increased width as well as rigidity and stability due to a three-layer design of silicone (outer and internal layers) and biocompatible Polyester (middle layer). One study on the implantation of ZSI 475 penile prosthesis in male subjects has been published to date. It identified 28 patients who had the ZSI 475 implanted between 2012 and 2016. At a mean follow-up of 35 months, patients reported a mean satisfaction rating of $93 \%$. There were three complications reported: one patient developed a scrotal hematoma, one needed a full prosthesis replacement due to a tubing breakage and the third required surgical intervention to adjust pump positioning (52).

\section{Surgical considerations and post-operative results for three-piece implants Cylinders}

IPP cylinder implantation can be complicated in cases of corporal fibrosis-a process in which smooth muscle is replaced by fibrotic tissue-which can occur from varying causes including diabetes, prior intracorporal injection therapy, ischemic priapism, and PD (41). In more difficult fibrosis cases-cavernotomes, or beveled rasping tools, can be used to core out a tunnel suitable to house a penile implant. Other techniques which have been investigated 
to accommodate implants in patients with fibrotic corpora include extended/wider incisions, multiple incision methods, and corporal counter incisions. The use of synthetic grafting materials has fallen out of practice due to high rates of patient infection (up to 50\%) (53). Smaller implants can also be placed in patients with more serious cases of fibrosis-either permanently or to progressively expand the corporal tunnel to allow for replacement with a larger implant in the future (41). The AMS 700CX and Coloplast Titan have been investigated for prosthesis implantations in PD patients which required adjuvant modeling (bending of penis in opposition to pathologic curve) procedures during surgery. Of $138 \mathrm{PD}$ patients implanted with either the AMS 700 CX (88 patients) or Coloplast Titan (50 patients), there were no statistically significant difference in device survival. Two prostheses were removed because of infection and eight required revision surgery for device malfunction (54).

Glans hypermobility may be caused by inadequate prosthesis cylinder sizing or positioning, though can also be due to anatomic variation, whereby a patient's corpora do not fully extend to the distal glans (41). If the defect does not correct during the healing process, a surgical solution may be required. In this procedure, a hemi-circumcisional incision is made opposing the tilting direction, and the glans is dissected from the distal tips of the corpora while the cylinders are inflated-permanent sutures are placed to anchor the glans to the distal tunica albuginea (41).

The most common complaint associated with penile prosthesis surgery is the perception of lost penile lengthwhich may be due to the lack of glans engorgement (55). Urologists have published results of surgical penile length preservation and restoration techniques at the time of prosthesis implantation, including the sliding, modified sliding, and multiple slice techniques. These surgical procedures involved more complex and risky steps, including: penile degloving, mobilization of the dorsal neurovascular bundle, dissection and separation of corpus spongiosum tissue from the cavernosal bodies, and finally, incisions through the Buck's fascia of the corporal bodies to release them, allowing for penile lengthening (55). For three-piece IPPs placement in patients without preexisting fibrosis, $\mathrm{PD}$, or other corporal defects, other penile length conservation procedures are also studied, including aggressive cylinder sizing or the "new length measurement technique NLMT" in conjunction with postoperative rehabilitation inflation protocol (56-58).

\section{Infection control}

Skin flora account for the primary groups of bacteria responsible for prosthesis infections (59). To decrease this risk of infection, the "no-touch" technique utilizes a draped fenestration to prevent any contact between the patient's skin and the surgeon or instruments. Eid et al. studied infection rates seen with antibiotic coated devices implanted by a single surgeon between 2002 and 2011 . The study concluded that antibiotic coated implants lower infection risk from $5.3 \%$ to $2 \%$, while the "no-touch" technique lowered infection rates to $0.46 \%$ (60). There were no significant differences between AMS and Coloplast devices with respect to infection rate. Dhabuwala et al. have compared infection rates of different antibiotic solutions in penile surgery. Though no statistically significant results were found, Titan Coloplast implant infection rates by antibiotic combination were: $4.4 \%$ for vancomycin/ gentamycin, $0 \%$ rifampin/gentamicin; the AMS Inhibizonecoated implant infection rate was $1.3 \%$ (47).

New research in antibacterial coatings of penile prostheses emphasizes the need to account for the potential of fungus and non-traditional bacterial attack when choosing antibiotic dips. While gram positive staph epidermidis is considered the most common culprit in infected implants, studies indicate the bacterial compositions of IPP biofilms appear to be changing: including noted trends of reduced gram positive bacteria and proliferation of gram negative bacteria and fungi in coated implants at the time of revisionary surgery (48,61-63). A multi-center study of penile prosthesis infections concludes that $14-38 \%$ of prosthesis infections involve micro-organisms not covered by current AUA and EUA antibiotic guidelines, highlighting the continued vigilance in improving surgical technique and medical management of infection (64).

\section{Reservoirs}

Traditionally, reservoirs in three-piece IPPs are placed in the space of Retzius as it is imperceptible to the patient. In patients with a history of pelvic surgery or radiation, placement in the space of Retzius is high risk and the reservoir is alternative, ectopic locations such as a high submuscular placement $(65,66)$. Another ectopic reservoir placements is subcutaneous, for obese patients (67-69). The decision of where to place the reservoir is usually made preoperatively, but can also be decided intraoperatively after observing a patient's anatomy (36). Though rare, intra- and post-operative reservoir complications do occur, including: inguinal herniation, bowel/bladder erosion, auto-inflation, and infection (65). These risks may be increased in patients which have had robotic assisted laparoscopic prostatectomy, which can destroy the space of Retzius (65). In the case of 
any injury to the bladder during prosthesis placement or erosion into the bladder post-operatively, contralateral or ectopic placement of the reservoir can be performed (70). Reservoir migration through the inguinal canal is a rare occurrence, with reported rates of $0.09 \%$ to $1.2 \%$ in Space of Retzius placement, and $1.4 \%$ in alternative reservoir placements (71). Reservoir herniation requires either reservoir replacement or repositioning through an inguinal incision-and techniques including a purse string suture to support the inguinal ring or higher inguinal canal placement ( $\geq 4$ inches) are described in the literature $(72,73)$. Surgical results from three-piece IPP implantation procedures are presented in Table 4 (35,54,74-85).

\section{Penile prosthesis in phalloplasty}

Gender reassignment surgery is a very complicated process that commonly involves several sub-procedures including penile urethroplasty, urethral lengthening, scrotoplasty, hysterectomy and oophorectomy, and testicular implants. The goals of phalloplasty are fabrication of a life-like penis with tactile and erogenous sensation, ability to stand during micturition, and the potential for erection and penetrative intercourse (86). In gender-affirming surgeries with neophallus construction, many patients require a penile prosthesis as a last step to be able to engage in sexual intercourse. Radial forearm flap phalloplasty with a simultaneous urethral reconstruction using the "tube within tube" technique is considered the current standard procedure female to male reassignment surgery. Other anatomic locations which can be used for tissue donation during phalloplasty include the anterolateral thigh, abdomen, superficial circumflex iliac artery perforator flap, and thoracodorsal artery perforator flap $(87,88)$.

There are several complications associated with neophallus placement in gender reassignment, including partial/full phallic loss, infection, supersonic transporter deformity, hematoma, wound dehiscence, and urinary fistula and stricture complications $(86,89)$. These complications are associated with the increased difficulty of gender reassignment surgeries with respect to existing patient anatomy. In comparison with prosthesis placement in cis males, transgender patients do not have corpora cavernosa or a crus of the penis, have different transplanted tissue at the site of the phallus, and also have implants placed in an area which has been previously operated on extensively with increased amounts of scar tissue and less vascularization (90).

\section{Results from neophallus penile prosthesis implantation}

The first report of prosthesis implantation in a female to male transgender patient was described by Puckett and Montie in 1978 (91). There are several retrospective studies comparing post-operative outcomes of gender affirming surgeries that used different types of penile prostheses. Zuckerman et al. analyzed results from 21 patients receiving malleable implants (Duraphase or Spectra) and 10 receiving inflatable prostheses (AMS CX/CXR or Coloplast Titan). The post-operative complication rate was $23 \%$ at median 5.5-month follow-up. Complications included the explantation of five prostheses (two of which were replaced) due to infection or erosion (92). Interestingly, researchers noted that $81 \%$ of patients were sexually active at 60 months after follow-up. The researchers conclude the study endorsing IPPs for neophallus implants, as the option of deflating the IPP can reduce pressure on the distal neophallus and decrease risk of erosion.

Hoebeke $e t$ al. published results from the implantation of ten one-piece Dynaflex (withdrawn from market in 1997) and 25 three-piece AMS prostheses between 1996 and 2001. Of the ten one-piece devices, one was explanted due to mechanical failure and another was removed due to infection. At a mean follow-up of 3.5 years, the remaining eight patients had a working one-piece prosthesis in place. Of the 25 three-piece IPPs placed, four prostheses were removed due to infection and one was removed due to mechanical failure (93).

The same team published a larger study in 2010 - the largest series on transsexual males to date-that looked at results from penile prosthesis implantation in 129 patients between 1996 and 2007. Dynaflex (n=9), AMS threepiece CX/CXM ( $\mathrm{n}=50)$, AMS CX with Inhibizone ( $\mathrm{n}=17)$, Ambicor $(n=47)$, and Coloplast $(n=6)$ prostheses were placed in the study (90). Results from this study were presented according to prosthesis type in several categories: infection, protrusion, leak, dysfunction, malposition, and "other". The Dynaflex prosthesis had the highest rate of mechanical dysfunction (53.3\%) among the placed devices, while the AMC Ambicor had the lowest rate of mechanical dysfunction $(0 \%)$. Nearly $55 \%(n=38)$ of AMS threepiece devices without Inhibizone required explantation due to infection $(n=9)$, protrusion $(n=7)$, leakage $(n=12)$, or dysfunction $(\mathrm{n}=10)$. A lower percentage of three-piece AMS CX Inhibizone prostheses required explantationof 34 implants 12 were explanted (35.3\%) because of infection $(n=2)$, leakage $(n=3)$, mechanical dysfunction $(n=4)$, 


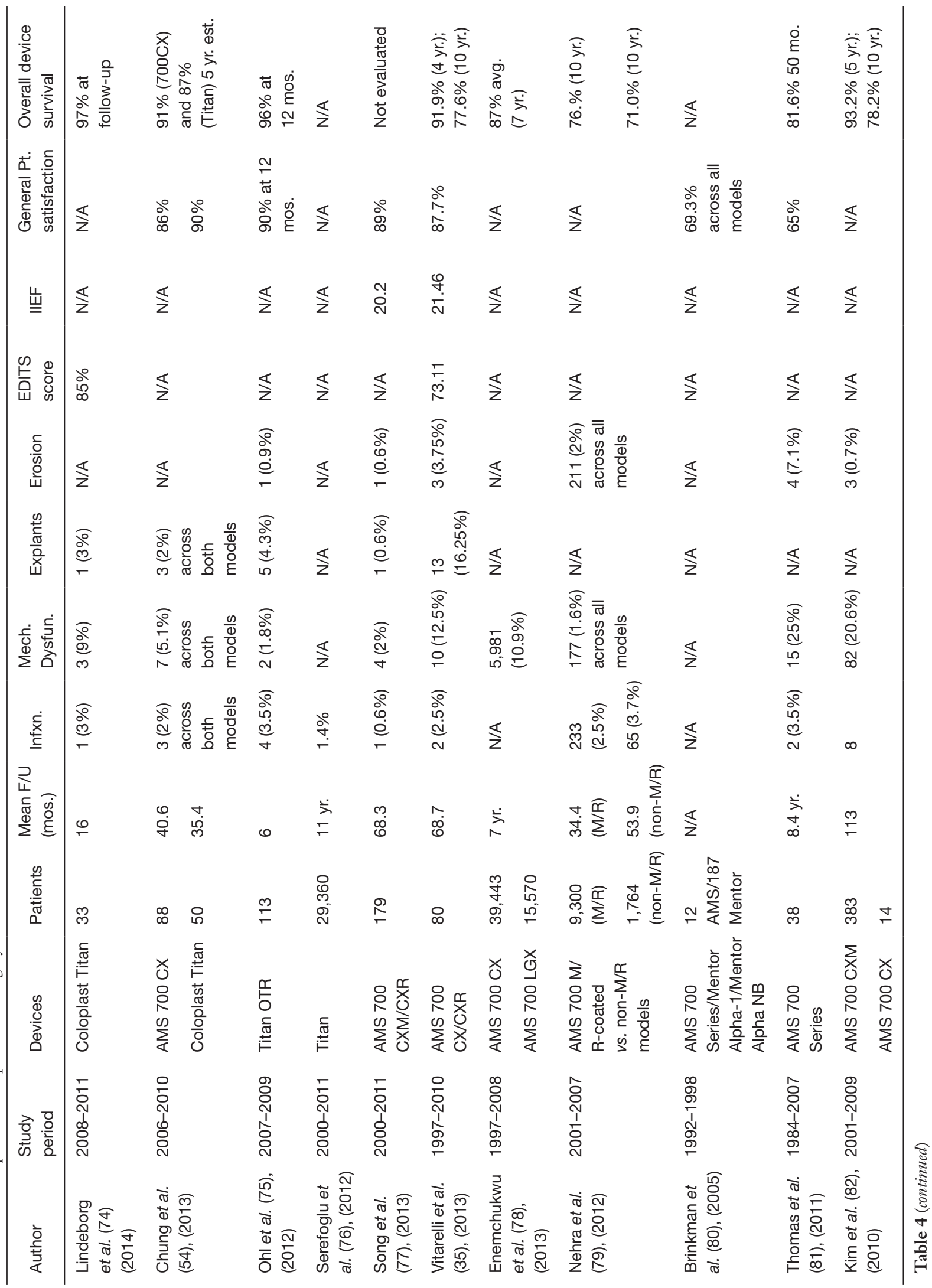




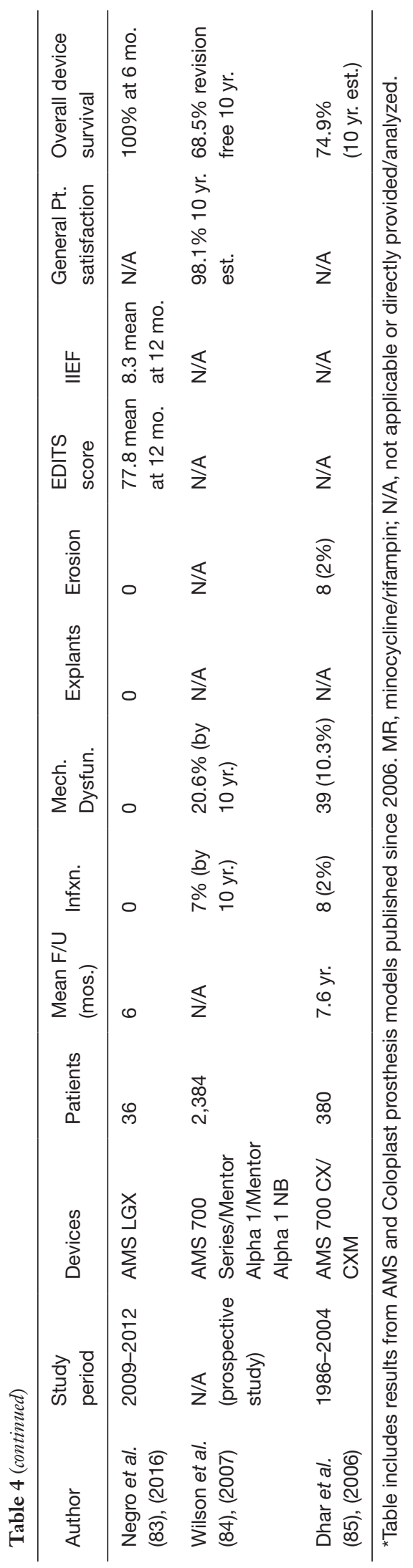

and protrusion ( $n=3)(90)$. Researchers identified higher infection rates for all prostheses implanted in neophalluses when compared with prostheses implanted in cis males (13\% vs. 3.2\% for non-coated three-piece devices). This important study highlights the need for improvements in infection prevention, prosthesis placement, and implant mechanical reliability in neophallic prosthetic placement.

Most recently, in 2019, results were released from a retrospective cohort study of 32 transgender men who elected to have a variety of penile prosthesis implants placed between 1989 and 2018 (94). The Coloplast Genesis $(n=14)$, AMS Dynaflex $(n=13)$, AMS Ambicor $(n=3)$, and AMS Spectra $(n=2)$ implants were placed. Of the originally implanted prostheses, $16(50 \%)$ were replaced or removed after a median of 1.1 years. Five of the devices were explanted because of infection. Despite this study being one of the most recent publications in the field of penile prosthetics on gender reassignment surgeries, it lacks data from more recent two and three-piece prosthesis models. Table 5 presents important post-operative metrics by prosthesis type and model from all available published studies on penile implants in female to male neophallus prosthesis implantation (90,95-100).

\section{Female to male specific penile prosthesis}

The ZSI $100 \mathrm{FtM}$ implant is a malleable penile prosthesis specifically designed for female to male phalloplasty. The prosthesis is secured through a proximal plate composed of steel and covered with silicone is secured to the patient's pubic bone. The body of the neophallus is composed of a stainless-steel core surrounded by a medical grade silicone shell. The implant is designed to achieve an erect state through manipulation with one hand. A 2019 study examines surgical results for patients implanted with the ZSI FtM device, following prior phalloplasty through one of various methods (the majority of patient underwent combination, anterolateral thigh flap, or radial forearm flap phalloplasty). The mean time between phalloplasty and prosthesis placement was around 3.5 years. In a mean follow-up time of 6 months, the prosthesis was explanted in $11 / 25$ patients-due to infection $(n=3)$, protrusion $(\mathrm{n}=4)$, pubic pain $(\mathrm{n}=1)$, and general difficulty living with the implant (n=3) (52). Researchers noted that patients complained about getting used to the implant, about difficulty "hiding" implants in shorter neophalluses due to limited bending, and about pain experienced by patients due to the "quite large" fixation plate which is attached to the pubic periosteum (52). 


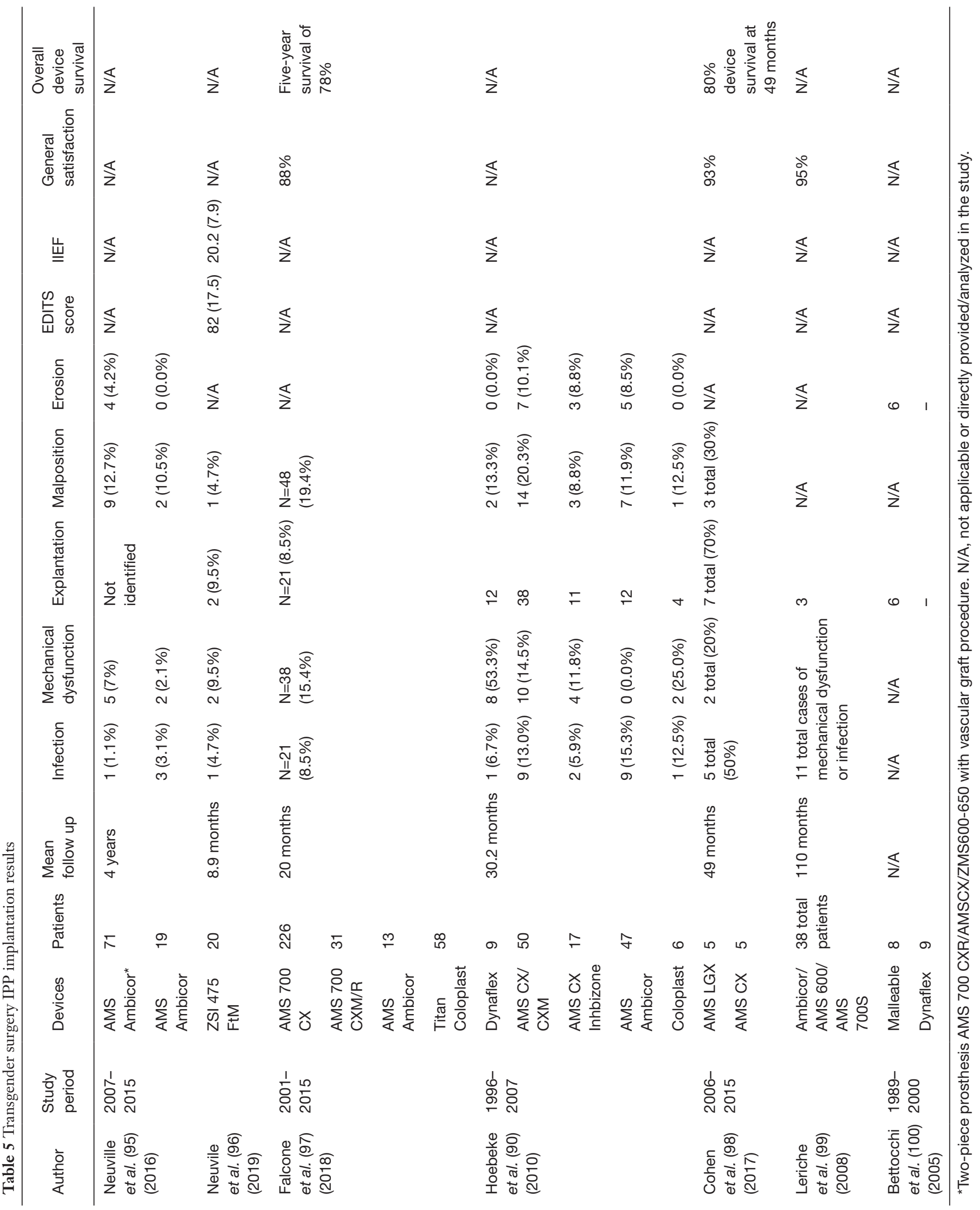




\section{Conclusions}

Several surgical and technological advances have revolutionized the penile prosthetic implant since the early 1980s. The discovery and application of advanced polymeric prosthetic materials, antibiotic coatings, and increased length and width options have increased functionality, strength, and device lifetimes. At the same time, these advances have reduced both infections and overall complication rates (101). Studies on the latest iterations of the three penile prosthetic device types indicate patient satisfaction ratings consistently above at or above $75 \%$. Provided a patient is a suitable candidate for a threepiece IPP, many experts consider this device type to be the highest standard for biological mimicry of an erect human penis. While there is apparent consensus that that the three-piece implant is a high-quality option for female to male transgender surgery, limited studies on the efficacy of these prosthetic devices in transgender patients were found upon completion of this review. All of the available data on penile prostheses in gender affirmation surgery comes from retrospective studies. Their findings indicate that infection and complication rates are higher in transgender prosthesis placement surgeries than in implantations in cis males. Results from any future randomized clinical trials of prosthesis implants in transgender patients would help further clarify the best prosthesis options for this patient population. There is very limited research on the ZSI 475 $\mathrm{FtM}$, the first prosthesis specifically designed for female to male phalloplasty. Preliminary results indicate a lower infection rate $(4.7 \%)$ than seen in studies implanting other prostheses. Still, the infection rates are nearly double those reported for three-piece IPP in the cis males, highlighting the need for continued research and development of the more successful penile implantation options for genderreassigned males.

\section{Acknowledgments}

Funding: None.

\section{Footnote:}

Provenance and Peer Review: This article was commissioned by the Guest Editors (Francisco E. Martins and Tobias S. Köhler) for the series "Controversies and Considerations of Penile Surgery" published in Translational Andrology and Urology. The article has undergone external peer review.
Reporting Checklist: The authors have completed the Narrative Review Reporting Checklist. Available at: http:// dx.doi.org/10.21037/tau-20-1279

Conflicts of Interest: The authors have completed the ICMJE uniform disclosure form (available at http://dx.doi. org/10.21037/tau-20-1279). The series "Controversies and Considerations of Penile Surgery" was commissioned by the editorial office without any funding or sponsorship. The authors have no other conflicts of interest to declare.

Ethical Statement: The authors are accountable for all aspects of the work in ensuring that questions related to the accuracy or integrity of any part of the work are appropriately investigated and resolved.

Open Access Statement: This is an Open Access article distributed in accordance with the Creative Commons Attribution-NonCommercial-NoDerivs 4.0 International License (CC BY-NC-ND 4.0), which permits the noncommercial replication and distribution of the article with the strict proviso that no changes or edits are made and the original work is properly cited (including links to both the formal publication through the relevant DOI and the license). See: https://creativecommons.org/licenses/by-nc-nd/4.0/.

\section{References}

1. Mulcahy JJ. The Development of Modern Penile Implants. Sex Med Rev 2016;4:177-89.

2. Kocjancic E, Iacovelli V. Penile Prostheses. Clin Plast Surg 2018;45:407-14.

3. Martinez DR, Terlecki R, Brant WO. The Evolution and Utility of the Small-Carrion Prosthesis, Its Impact, and Progression to the Modern-Day Malleable Penile Prosthesis. J Sex Med 2015;12 Suppl 7:423-30.

4. Levine LA, Becher EF, Bella AJ, et al. Penile Prosthesis Surgery: Current Recommendations From the International Consultation on Sexual Medicine. J Sex Med 2016;13:489-518.

5. Montague DK. Experience with Jonas malleable penile prosthesis. Urology 1984;23:83-5.

6. Dorflinger T, Bruskewitz R. AMS malleable penile prosthesis. Urology 1986;28:480-5.

7. Verze P, Capece M, Califano G, et al. Two-piece inflatable and semi-rigid penile implants: an effective alternative? Int J Impot Res 2020;32:24-9. 
8. Kim YD, Yang SO, Lee JK, et al. Usefulness of a malleable penile prosthesis in patients with a spinal cord injury. Int J Urol 2008;15:919-23.

9. Le BV, McVary KT, McKenna K, et al. Use of Magnetic Induction to Activate a "Touchless" Shape Memory Alloy Implantable Penile Prosthesis. J Sex Med 2019;16:596-601.

10. Le B, McVary K, McKenna K, et al. A Novel Thermalactivated Shape Memory Penile Prosthesis: Comparative Mechanical Testing. Urology 2017;99:136-41.

11. Trost L. Future considerations in prosthetic urology. Asian J Androl 2020;22:70-5.

12. Salem EA, Wilson SK, Neeb A, et al. Mechanical reliability of AMS $700 \mathrm{CX}$ improved by parylene coating. J Sex Med 2009;6:2615-20.

13. Mulcahy JJ. Current approach to the treatment of penile implant infections. Ther Adv Urol 2010;2:69-75.

14. Gross MS, Phillips EA, Balen A, et al. The Malleable Implant Salvage Technique: Infection Out-comes after Mulcahy Salvage Procedure and Replacement of Infected Inflatable Penile Pros-thesis with Malleable Prosthesis. J Urol 2016;195:694-7.

15. Mulcahy JJ. Penile implant infections: prevention and treatment. Curr Urol Rep 2008;9:487-91.

16. Chiang HS, Wu CC, Wen TC, et al. 10 years of experience with penile prosthesis implantation in Taiwanese patients. J Urol 2000;163:476-80.

17. Salama N. Satisfaction with the malleable penile prosthesis among couples from the Middle East--is it different from that reported elsewhere? Int J Impot Res 2004;16:175-80.

18. Minervini A, Ralph DJ, Pryor JP. Outcome of penile prosthesis implantation for treating erectile dysfunction: experience with 504 procedures. BJU Int 2006;97:129-33.

19. Falcone M, Rolle L, Ceruti C, et al. Prospective analysis of the surgical outcomes and patients' satisfaction rate after the AMS Spectra penile prosthesis implantation. Urology 2013;82:373-6.

20. Bozkurt IH, Arslan B, Yonguc T, et al. Patient and partner outcome of inflatable and semi-rigid penile prosthesis in a single institution. Int Braz J Urol 2015;41:535-41.

21. Anafarta K, Yaman O, Aydos K. Clinical experience with Dynaflex penile prostheses in 120 pa-tients. Urology 1998;52:1098-100.

22. Wilson SK, Henry GD, Delk JR Jr, et al. The mentor Alpha 1 penile prosthesis with reservoir lock-out valve: effective prevention of auto-inflation with improved capability for ectopic res-ervoir placement. J Urol 2002;168:1475-8.

23. Kim SC. Mechanical reliability of AMS hydraulic penile prostheses. J Korean Med Sci 1995;10:422-5.

24. Abbosh PH, Thom MR, Bullock A. Laparascopic capsulotomy to treat autoinflation of inflatable penile prostheses. J Sex Med 2012;9:1212-5.

25. Jensen JB, Larsen EH, Kirkeby HJ, et al. Clinical experience with the Mentor Alpha-1 inflatable penile prosthesis: report on 65 patients. Scand J Urol Nephrol 2005;39:69-72.

26. Ko OS, Bennett NE Jr. Ambicor Two-Piece Inflatable Penile Prosthesis: Background and Con-temporary Outcomes. Sex Med Rev 2018;6:319-27.

27. Lux M, Reyes-Vallejo L, Morgentaler A, et al. Outcomes and satisfaction rates for the rede-signed 2-piece penile prosthesis. J Urol 2007;177:262-6.

28. Abdelsayed GA, Levine LA. Ambicor 2-Piece Inflatable Penile Prosthesis: Who and How? J Sex Med 2018;15:410-5.

29. Gentile G, Franceschelli A, Massenio P, et al. Patient's satisfaction after 2-piece inflatable pe-nile prosthesis implantation: An Italian multicentric study. Arch Ital Urol Androl 2016;88:1-3.

30. Levine LA, Estrada CR, Morgentaler A. Mechanical reliability and safety of, and patient satis-faction with the Ambicor inflatable penile prosthesis: results of a 2 center study. J Urol 2001;166:932-7.

31. Natali A, Olianas R, Fisch M. Penile implantation in Europe: successes and complications with 253 implants in Italy and Germany. J Sex Med 2008;5:1503-12.

32. Wilson SK, Wahman GE, Lange JL. Eleven years of experience with the inflatable penile pros-thesis. J Urol 1988;139:951-2.

33. Pastuszak AW, Lentz AC, Farooq A, et al. Technological Improvements in Three-Piece Inflatable Penile Prosthesis Design over the Past 40 Years. J Sex Med 2015;12 Suppl 7:415-21.

34. Eid JF. What is new for inflatable penile prostheses? Curr Opin Urol 2009;19:582-8.

35. Vitarelli A, Divenuto L, Fortunato F, et al. Long term patient satisfaction and quality of life with AMS700CX inflatable penile prosthesis. Arch Ital Urol Androl 2013;85:133-7.

36. Henry GD, Laborde E. A review of surgical techniques for impending distal erosion and in-traoperative penile implant complications: part 2 of a three-part review series on penile prosthetic surgery. J Sex Med 2012;9:927-36.

37. Thirumavalavan N, Cordon BH, Gross MS, et al. Rear Tip Extenders and Penile Prosthesis Rigid-ity: A Laboratory Study of Coloplast Prostheses. J Sex Med 2018;15:1030-3. 
38. Thirumavalavan N, Cordon BH, Gross MS, et al. The Rear Tip Extender for Inflatable Penile Prostheses: Introduction of "Rigidity Factor" and Review of the Literature. Sex Med Rev 2019;7:516-20.

39. Milbank AJ, Montague DK, Angermeier KW, et al. Mechanical failure of the American Medical Systems Ultrex inflatable penile prosthesis: before and after 1993 structural modification. J Urol 2002;167:2502-6.

40. Kim KS, Bae WJ, Kim SW, et al. Experience with AMS 700 LGX penile prostheses for preserving penile length in Korea. BMC Urol 2019;19:6.

41. Scherzer ND, Dick B, Gabrielson AT, et al. Penile Prosthesis Complications: Planning, Prevention, and Decision Making. Sex Med Rev 2019;7:349-59.

42. Dick B, Tsambarlis P, Reddy A, et al. An update on: longterm outcomes of penile prostheses for the treatment of erectile dysfunction. Expert Rev Med Devices 2019;16:281-6.

43. Wilson SK, Zumbe J, Henry GD, et al. Infection reduction using antibiotic-coated inflatable pe-nile prosthesis. Urology 2007;70:337-40.

44. Carson CC 3rd. Efficacy of antibiotic impregnation of inflatable penile prostheses in decreasing infection in original implants. J Urol 2004;171:1611-4.

45. Wolter CE, Hellstrom WJ. The hydrophilic-coated inflatable penile prosthesis: 1-year experi-ence. J Sex Med 2004;1:221-4.

46. Wilson SK, Salem EA, Costerton W. Anti-infection dip suggestions for the Coloplast Titan In-flatable Penile Prosthesis in the era of the infection retardant coated implant. J Sex Med 2011;8:2647-54.

47. Dhabuwala C, Sheth S, Zamzow B. Infection rates of rifampin/gentamicin-coated Titan Colo-plast penile implants. Comparison with Inhibizone-impregnated AMS penile implants. J Sex Med 2011;8:315-20.

48. Lokeshwar SD, Bitran J, Madhusoodanan V, et al. A Surgeon's Guide to the Various Antibiotic Dips Available During Penile Prosthesis Implantation. Curr Urol Rep 2019;20:11.

49. Delk J, Knoll LD, McMurray J, et al. Early experience with the American Medical Systems new tactile pump: results of a multicenter study. J Sex Med 2005;2:266-71.

50. Hakky T, Lentz A, Sadeghi-Nejad H, et al. The Evolution of the Inflatable Penile Prosthesis Res-ervoir and Surgical Placement. J Sex Med 2015;12 Suppl 7:464-7.

51. Karpman E, Sadeghi-Nejad H, Henry G, et al. Current opinions on alternative reservoir place-ment for inflatable penile prosthesis among members of the Sexual Medicine
Society of North America. J Sex Med 2013;10:2115-20.

52. Blewniewski M, Ostrowski I, Pottek T, et al. Safety and efficacy outcomes of ZSI 475 penile prosthesis. Urologia 2017;84:98-101.

53. Trost L, Hellstrom WJ. History, Contemporary Outcomes, and Future of Penile Prostheses: A Review of the Literature. Sex Med Rev 2013;1:150-63.

54. Chung E, Solomon M, DeYoung L, et al. Comparison between AMS 700 ${ }^{\mathrm{TM}} \mathrm{CX}$ and Coloplast ${ }^{\mathrm{TM}}$ Titan inflatable penile prosthesis for Peyronie's disease treatment and remodeling: clinical outcomes and patient satisfaction. J Sex Med 2013;10:2855-60.

55. Tran H, Goldfarb R, Ackerman A, et al. Penile Lengthening, Girth, and Size Preservation at the Time of Penile Prosthesis Insertion. Sex Med Rev 2017;5:403-12.

56. Henry G, Houghton L, Culkin D, et al. Comparison of a new length measurement technique for inflatable penile prosthesis implantation to standard techniques: outcomes and patient satis-faction. J Sex Med 2011;8:2640-6.

57. Henry GD, Carrion R, Jennermann C, et al. Prospective evaluation of postoperative penile re-habilitation: penile length/girth maintenance 1 year following Coloplast Titan inflatable penile prosthesis. J Sex Med 2015;12:1298-304.

58. Hakky TS, Wang R, Henry GD. The evolution of the inflatable penile prosthetic device and sur-gical innovations with anatomical considerations. Curr Urol Rep 2014;15:410.

59. Swanton AR, Munarriz RM, Gross MS. Updates in penile prosthesis infections. Asian J Androl 2020;22:28-33.

60. Eid JF, Wilson SK, Cleves M, et al. Coated implants and "no touch" surgical technique decreases risk of infection in inflatable penile prosthesis implantation to $0.46 \%$. Urology 2012;79:1310-5.

61. Gross MS, Reinstatler L, Henry GD, et al. Multicenter Investigation of Fungal Infections of In-flatable Penile Prostheses. J Sex Med 2019;16:1100-5.

62. Jani K, Smith C, Delk JR 2nd, et al. Infection Retardant Coatings Impact on Bacterial Presence in Penile Prosthesis Surgery: A Multicenter Study. Urology 2018;119:104-8.

63. Dawn LE, Henry GD, Tan GK, et al. Biofilm and Infectious Agents Present at the Time of Penile Prosthesis Revision Surgery: Times Are a Changing. Sex Med Rev 2017;5:236-43.

64. Gross MS, Phillips EA, Carrasquillo RJ, et al. Multicenter Investigation of the Micro-Organisms Involved in Penile Prosthesis Infection: An Analysis of the Efficacy of the AUA and EAU Guide-lines for Penile Prosthesis Prophylaxis. J Sex Med 2017;14:455-63. 
65. Levine LA, Hoeh MP. Review of penile prosthetic reservoir: complications and presentation of a modified reservoir placement technique. J Sex Med 2012;9:2759-69.

66. Perito PE. Ectopic reservoir placement--no longer in the space of Retzius. J Sex Med 2011;8:2395-8.

67. Garber BB, Gross MS, Stember D. Sub-external oblique placement of inflatable penile prosthe-sis reservoirs-initial experience. Int J Impot Res 2019;31:400-3.

68. Garber BB, Bickell M. Subcutaneous Placement of Inflatable Penile Prosthesis Reservoirs. Urology 2016;88:93-6.

69. Smaldone MC, Cannon GM Jr, Benoit RM. Subcutaneous reservoir placement during penile prosthesis implantation. Can J Urol 2006;13:3351-2.

70. Sharma D, Smith RP. Troubleshooting intraoperative complications of penile prosthesis place-ment. Transl Androl Urol 2017;6:S892-7.

71. Clavell-Hernández J, Shah A, Wang R. Non-Infectious Reservoir-Related Complications During and After Penile Prosthesis Placement. Sex Med Rev 2019;7:521-9.

72. Karpman E, Brant WO, Kansas B, et al. Reservoir alternate surgical implantation technique: preliminary outcomes of initial PROPPER study of low profile or spherical reservoir implanta-tion in submuscular location or traditional prevesical space. J Urol 2015;193:239-44.

73. Mulcahy JJ. The Prevention and Management of Noninfectious Complications of Penile Im-plants. Sex Med Rev 2015;3:203-13.

74. Lindeborg L, Fode M, Fahrenkrug L, et al. Satisfaction and complications with the Titan ${ }^{\circledR}$ one-touch release penile implant. Scand J Urol 2014;48:105-9.

75. Ohl DA, Brock G, Ralph D, et al. Prospective evaluation of patient satisfaction, and surgeon and patient trainer assessment of the Coloplast titan one touch release three-piece inflatable pe-nile prosthesis. J Sex Med 2012;9:2467-74.

76. Serefoglu EC, Mandava SH, Gokce A, et al. Long-term revision rate due to infection in hydro-philic-coated inflatable penile prostheses: 11-year follow-up. J Sex Med 2012;9:2182-6.

77. Song WD, Yuan YM, Cui WS, et al. Penile prosthesis implantation in Chinese patients with se-vere erectile dysfunction: 10-year experience. Asian J Androl 2013;15:658-61.

78. Enemchukwu EA, Kaufman MR, Whittam BM, et al. Comparative revision rates of inflatable penile prostheses using woven Dacron ${ }^{\circledR}$ fabric cylinders. J Urol 2013;190:2189-93.
79. Nehra A, Carson CC 3rd, Chapin AK, et al. Long-term infection outcomes of 3-piece antibiotic impregnated penile prostheses used in replacement implant surgery. J Urol 2012;188:899-903.

80. Brinkman MJ, Henry GD, Wilson SK, et al. A survey of patients with inflatable penile prostheses for satisfaction. J Urol 2005;174:253-7.

81. Thomas AZ, Carrol R, Manecksha RP, et al. Extended long term functional outcome of inflata-ble penile prosthesis in a single institution. Ir Med J 2011;104:53-5.

82. Kim DS, Yang KM, Chung HJ, et al. AMS 700CX/CXM inflatable penile prosthesis has high me-chanical reliability at long-term follow-up. J Sex Med 2010;7:2602-7.

83. Negro CL, Paradiso M, Rocca A, et al. Implantation of AMS 700 LGX penile prosthesis preserves penile length without the need for penile lengthening procedures. Asian J Androl 2016;18:114-7.

84. Wilson SK, Delk JR, Salem EA, et al. Long-term survival of inflatable penile prostheses: single surgical group experience with 2,384 first-time implants spanning two decades. J Sex Med 2007;4:1074-9.

85. Dhar NB, Angermeier KW, Montague DK. Long-term mechanical reliability of AMS 700CX/CXM inflatable penile prosthesis. J Urol 2006;176:2599-601; discussion 2601.

86. Heston AL, Esmonde NO, Dugi DD 3rd, et al. Phalloplasty: techniques and outcomes. Transl Androl Urol 2019;8:254-65.

87. Manero I, Labanca T, Trivino JM. Aesthetic Refinements after Radial Free Flap Phalloplasty: Optimizing the Donor Site and the Phallus. Plast Reconstr Surg Glob Open 2017;5:e1611.

88. Djordjevic ML, Bencic M, Kojovic V, et al. Musculocutaneous latissimus dorsi flap for phallo-plasty in female to male gender affirmation surgery. World J Urol 2019;37:631-7.

89. Salgado CJ, Fein LA, Williams EA, et al. Supersonic Transporter Deformity in Transgender Men following Phalloplasty. Plast Reconstr Surg 2019;144:225-7.

90. Hoebeke PB, Decaestecker K, Beysens M, et al. Erectile implants in female-to-male transsexu-als: our experience in 129 patients. Eur Urol 2010;57:334-40.

91. Puckett CL, Montie JE. Construction of male genitalia in the transsexual, using a tubed groin flap for the penis and a hydraulic inflation device. Plast Reconstr Surg 1978;61:523-30.

92. Zuckerman JM, Smentkowski K, Gilbert D, et al. Penile Prosthesis Implantation in Patients with a History of Total Phallic Construction. J Sex Med 2015;12:2485-91. 
93. Hoebeke P, de Cuypere G, Ceulemans P, et al. Obtaining rigidity in total phalloplasty: experi-ence with 35 patients. J Urol 2003;169:221-3.

94. van der Sluis WB, Pigot GLS, Al-Tamimi M, et al. A Retrospective Cohort Study on Surgical Out-comes of Penile Prosthesis Implantation Surgery in Transgender Men After Phalloplasty. Urology 2019;132:195-201.

95. Neuville P, Morel-Journel N, Maucourt-Boulch D, et al. Surgical Outcomes of Erectile Implants After Phalloplasty: Retrospective Analysis of 95 Procedures. J Sex Med 2016;13:1758-64.

96. Neuville P, Morel-Journel N, Cabelguenne D, et al. First Outcomes of the ZSI 475 FtM, a Specific Prosthesis Designed for Phalloplasty. J Sex Med 2019;16:316-22.

97. Falcone M, Garaffa G, Gillo A, et al. Outcomes of inflatable penile prosthesis insertion in 247 patients

Cite this article as: Polchert M, Dick B, Raheem O. Narrative review of penile prosthetic implant technology and surgical results, including transgender patients. Transl Androl Urol 2021;10(6):2629-2647. doi: 10.21037/tau-20-1279 completing female to male gender reassignment surgery. BJU Int 2018;121:139-44.

98. Cohen AJ, Bhanvadia RR, Pariser JJ, et al. Novel Technique for Proximal Bone Anchoring of Pe-nile Prosthesis After Radial Forearm Free Flap Neophallus. Urology 2017;105:2-5.

99. Leriche A, Timsit MO, Morel-Journel N, et al. Long-term outcome of forearm flee-flap phallo-plasty in the treatment of transsexualism. BJU Int 2008;101:1297-300.

100. Bettocchi C, Ralph DJ, Pryor JP. Pedicled pubic phalloplasty in females with gender dysphoria. BJU Int 2005;95:120-4.

101. Carvajal A, Benavides J, García-Perdomo HA, et al. Risk factors associated with penile prosthe-sis infection: systematic review and meta-analysis. Int J Impot Res 2020;32:587-97. 